\title{
"Idiopathic" Thrombosis in the Vertebrobasilar Arterial System in Young Men
}

\author{
D. I. GRAHAM, HUME ADAMS
}

British Medical fournal, 1972, 1, 26-28

\section{Summary}

Two young men died as a result of cerebellar infarction due to thrombosis in the vertebrobasilar arterial system in the absence of atheromatous stenosis, other identifiable intrinsic arterial disease, or embolism. In each case the swollen cerebellar infarct had produced tonsillar herniation and hydrocephalus.

\section{Introduction}

We have previously reported eight cases of fatal cerebral infarction due to thrombosis in the carotid arterial system in the absence of any intrinsic arterial disease or embolism (Adams and Graham, 1967). We now wish to report apparently idiopathic thrombosis in the vertebrobasilar system in two young men-cases of this type have not been reported previously-to support our earlier contention that there are as yet unidentified factors leading to thrombosis of major intracranial and extracranial cerebral arteries.

\section{Clinical Case Reports}

Case 1.-A 31-year-old man developed headache and vomiting six days before his death. At that time his blood pressure was 190/ $120 \mathrm{~mm} \mathrm{Hg}$. Treatment with methyldopa produced symptomatic relief but three days later he had a further episode of severe headache and vomiting accompanied by neck stiffness. He was found to be drowsy on admission to hospital but the only positive neurological abnormalities were neck stiffness and a left extensor plantar response. Lumbar puncture showed clear cerebrospinal fluid with a normal content of cells and sugar; the protein was $100 \mathrm{mg} / 100 \mathrm{ml}$. His condition deteriorated and he was transferred to the Institute of Neurological Sciences, Glasgow, by which time he was deeply unconscious and had bilateral fixed dilated pupils. The blood pressure remained raised at $190 / 120 \mathrm{~mm} \mathrm{Hg}$. Within an hour of admission to the institute he developed cardiorespiratory arrest and died.

Case 2.-A 29-year-old man was admitted to hospital with a long history of dyspepsia and severe abdominal pain of sudden onset. The clinical features were those of a perforated duodenal ulcer but this was not substantiated at laparotomy. He made a full and satisfactory recovery from an uneventful anaesthetic but six hours postoperatively became apnoeic and cyanosed. He was apparently successfully resuscitated from this episode but two hours later lapsed into coma and was found to have a flaccid quadriparesis, bilateral extensor plantar responses, small reacting pupils, and normal fundi. He was transferred on the same day to the institute. A left carotid angiogram and an air ventriculogram showed enlargement of the lateral ventricles. External ventricular drainage was set up. He continued to deteriorate and died four days later. The blood pressure remained within normal limits throughout the illness. \footnotetext{
Department of Neuropathology, Institute of Neurological Sciences,
Southern General Hospital, Glasgow S.W.1

D. I. GRAHAM, M.B., B.CH., M.R.C.PATH., Lecturer in Neuropathology HUME ADAMS, M.B.,Ch.B., PH.D.,M.R.C.PATH., Professor of Neuropathology
}

\section{Methods}

The comprehensive necropsy undertaken in each case included examination of the full length of the carotid and vertebral arteries. In both cases the arch of the aorta with the common, external, and internal carotid arteries and the proximal parts of the vertebral arteries attached were removed in one block and dissected after fixation. The upper seven cervical vertebrea, including the atlas, were removed as a single block with the main trunks of the vertebral arteries in situ. After fixation and decalcification this was cut into slices $1 \mathrm{~cm}$ thick and the vertebral arteries at every level (17 in Case 1 and 16 in Case 2) were examined histologically after staining with haematoxylin and eosin and by Weigert's method for elastic tissue.

Each brain was suspended in $10 \%$ formal saline for three weeks before dissection. The midbrain was transected and the cerebral hemispheres were cut in the coronal plane into slices $1 \mathrm{~cm}$ thick. After removing the cerebellum, the brain stem was cut horizontally at a number of levels. Representative blocks of the cerebral hemispheres, the cerebellum, and the brain stem were examined microscopically. All the major intracranial arteries were examined histologically by the serial block technique (Beesley and Daniel, 1956).

\section{Pathological Findings}

The only abnormalities detected outside the nervous system were enlargement of the heart $(440 \mathrm{~g})$ and some hypertrophy of the muscle of the left ventricle in Case 2. No source of embolism was identified in either case, nor was there any evidence of thrombosis, infarction, or any other significant abnormality in sections taken from many organs.

\section{NEUROPATHOLOGY}

In Case 1 (brain weight $1,670 \mathrm{~g}$ ) there was diffuse convolutional flattening. A tonsillar hernia was obvious but there was no tentorial hernia. The right posterior inferior cerebellar artery was occluded by recent thrombus (Fig. 1). In coronal sections of the cerebral hemispheres considerable enlargement of the lateral ventricles and of the third ventricle was found. In the cerebellum there was a recent pale and swollen infarct involving the greater part of the right hemisphere in the territory supplied by the posterior inferior cerebellar artery. The left hemisphere and the brain stem appeared normal. Microscopical examination confirmed that the right posterior inferior cerebellar artery was occluded by recent thrombus. Neither atheroma nor other intrinsic arterial disease was found in any of the intracranial arteries.

In Case 2 (brain weight $1,530 \mathrm{~g}$ ) there was again generalized convolutional flattening. A tonsillar hernia was obvious but a tentorial hernia was not present. Though the basilar and right vertebral arteries were occluded by recent thrombus, not a trace of atheroma was seen in any of the major vessels (Fig. 2). The left vertebral artery, which was much smaller than the right one, was patent. Coronal sections through the cerebral hemispheres showed that the previously enlarged lateral ventricles were now small and symmetrical as a result of the external ventricular drainage that had been established four days before death. There was massive recent pale infarction 
in both cerebellar hemispheres and in the pons and midbrain. The necrotic tissue was soft and swollen, and there was unusually severe cephalad displacement of the upper brain stem and the superior vermis to produce a reversed tentorial hernia. Histological examination confirmed that the right vertebral artery and the basilar artery were occluded by recent thrombus but showed no evidence of atheroma or other intrinsic arterial disease in any of the intracranial vessels.

In each case small plaques of atheroma were seen at the lower ends of the internal carotid arteries. Microscopical examination failed to show any evidence of intrinsic arterial disease in the vertebral arteries in the neck, apart from a solitary plaque of non-ulcerated atheroma in the right vertebral artery in Case 2 several centimetres below the level of occlusion by thrombus.

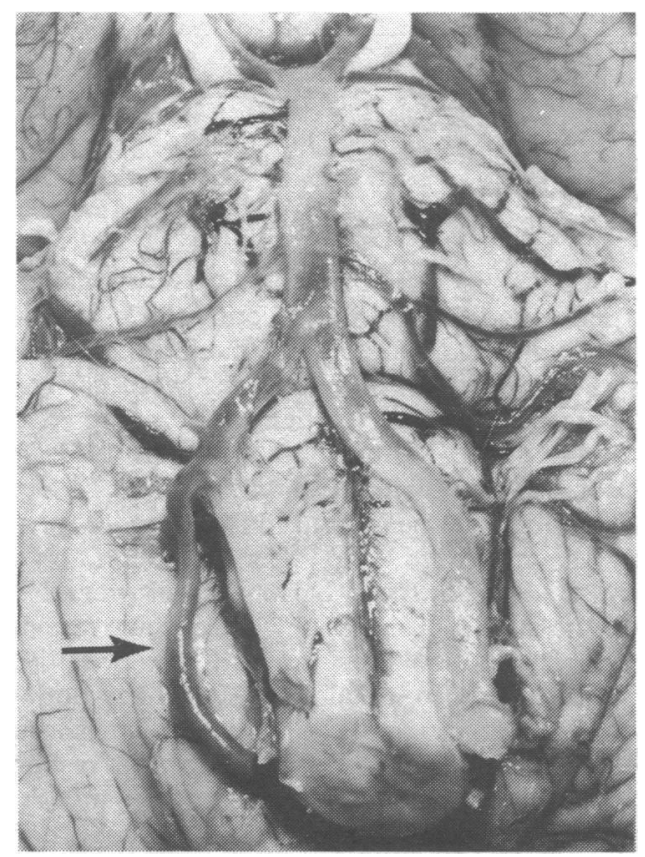

FIG. 1-Case 1. Right posterior inferior cerebellar artery (arrow) is occluded by thrombus. Note absence of atheroma.

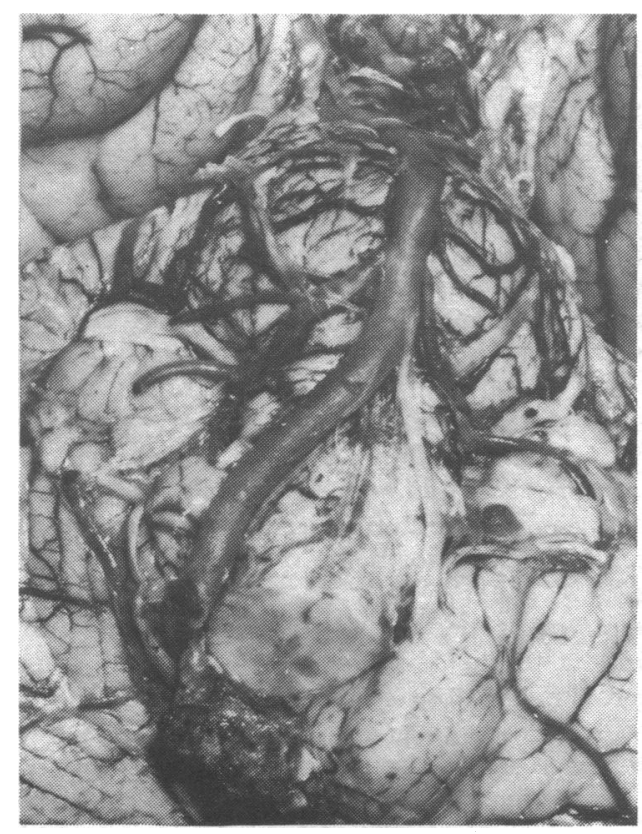

FIG. 2-Case 2. Right vertebral and basilar arteries are occluded by thrombus. Again note absence of atheroma.

\section{Discussion}

Few studies had been made on basilar artery occlusion until Kubik and Adams (1946) published clinical and pathological details of 18 cases. In 11 the occlusion was thrombotic and in seven embolic. In all the cases with thrombosis there was extensive atheroma of the basilar and other major cerebral arteries. Since then several series have been reported (DennyBrown, 1953; Fang and Palmer, 1956; Meyer et al., 1960; Fisher et al., 1961; Bradshaw and McQuaid, 1963; Dalal et al., 1968; Fisher, 1970) in all of which the most important aetiological factor was atherosclerosis with or without thrombotic occlusion. Other precipitating or associated factors such as arteritis, polycythaemia vera with thrombosis, cervical spondylosis, etc. have been described (Biemond, 1951; Cravioto et al. 1958; Williams and Wilson, 1962; Nagashima, 1970). Hypertension also seems to be an important factor (Silversides, 1954; Fang and Palmer, 1956; Duffy and Jacobs, 1958; Meyer et al., 1960), possibly by increasing the severity of atheroma.

In a review of non-embolic vertebrobasilar ischaemia in young adults Arriagada et al. (1962) reported nine cases in patients under the age of $\mathbf{4 0}$ years: a necropsy was performed in only one case and this disclosed infarction in the absence of intracranial arterial occlusion. In spite of the age of this group of patients, atheroma was thought to be the precipitating cause in six of the nine cases. The findings in other series have been similar (Berlin et al., 1955; Sprofkin and Blakey, 1956; Wells and Timberger, 1961; Louis and McDowell, 1967).

Cerebrovascular disease in infancy and childhood has been reviewed with regard to both the cervical and the intracranial arteries (Banker, 1961; Davie and Coxe, 1967) and in no instance was basilar or vertebral artery occlusion mentioned. A syndrome of obstruction of major cerebral vessels in early childhood without neurological signs (Prensky and Davis, 1970) has been described but its pathogenesis is still debatable. Dooley and Smith (1968) cited a single patient younger than 25 years with basilar artery occlusion and added the case of a 6-year-old boy in whom the pathogenesis was obscure. Included in the series of Meyer et al. (1960) is a 29-year-old diabetic with vertebrobasilar arterial insufficiency, and Luhan and Kaplan (1951) reported the case of a 25-year-old diabetic who died from atheroma of the right vertebral artery. It would therefore seem that even in young adults occlusion of the vertebrobasilar system is usually associated with atherosclerosis.

Studies of strokes in women of childbearing age (Cross et al., 1968; Amias, 1970; Schoenberg et al., 1970) have also incriminated occlusive vascular disease as the major aetiological factor, though there is increasing evidence that vertebrobasilar occlusion in otherwise healthy young women rarely occurs except in association with pregnancy and oral contraception (Stewart-Wallace, 1964; Bickerstaff and Holmes, 1967; Salmon et al., 1968). In the two cases described here the cause of the thrombosis is obscure. There was no source for embolism, nor was there any evidence of arterial disease or infarction in any other organ in the body.

In each case there was tonsillar herniation and hydrocephalus. Large acute infarcts in the cerebellum often act as expanding lesions, but though this is now generally accepted for acute infarcts in the cerebral hemispheres (Trotsenburg and Vinken, 1966; Adams and Graham, 1967), relatively little attention seems to have been paid to the occurrence of this phenomenon in the posterior fossa (Wood and Murphey, 1969).

We would like to thank our colleagues in the Institute of Neurological Sciences, Glasgow, for allowing us to quote from their records.

\section{References}

Adams, J. H., and Graham, D. I. (1967). Fournal of Neurology, Neurosurgery and Psychiatry, 30, 479.

Amias, A. G. (1970). Fournal of Obstetrics and Gynaecology of the British Commonwealth, 77, 312 . 
Arriagada, C. R., Hernandez, M. A. A., and Lagos, N. (1962). Neurocirugia, 20, 95 .

Banker, B. Q. (1961). Fournal of Neuropathology and Experimental Neurology, $20,127$.

Beesley, R. A., and Daniel, P. M. (1956). Fournal of Clinical Pathology, 9, 267 Berlin, L., Tumarkin, B., and Martin, H. L. (1955). New England Fournal of Medicine, 252, 162

Bickerstaff, E. R., and Holmes, J. M. (1967). British Medical Fournal, 1, 726. Biemond, A. (1951). Brain, 74, 300.

Bradshaw, P., and McQuaid, P. (1963). Quarterly fournal of Medicine, 32, 279.

Cravioto, H., Rey-Bellet, J., Prose, P. H., and Feigin, I. (1958). Neurology (Minneapolis), 8, 145 .

Cross, J. N., Castro, P. O., and Jennett, W. B. (1968). British Medical Fournal, 3, 214.

Dala, P. M., Shah, P. M., Anar, R. R., and Kikani, B. J. (1968). British Medical Yournal, 2, 769 .

Davie, J. C., and Core, W. (1967). Archives of Neurology, 17, 313.

Denny-Brown, D. (1953). Bulletin of the New England Medical Center,

15, 53.

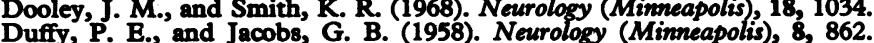

Fuffy, P. E.s and Jacobs, G. B. (1958). Neurology (Minneapolis), 8, 862

Fang, H. C. H., and Palmer, J. J. (1956). Neurology (
Fisher, C. M. (1970). Archives of Neurology, 22, 13.
Fisher, C. M., Karnes, W. E., and Kubik, C. S. (1961). Fournal of Neuropathology and Experimental Neurology, 20, 323.

Kubik, C. S., and Adams, R. D. (1946). Brain, 69, 73.

Louis, S., and McDowell, F. (1967). Annals of Internal Medicine, 66, 932

Luhan, J. A., and Kaplan, L. A. (1951). Archives of Neurology and Psychiatry, 66, 389.

Meyer, J. S., Sheehan, S., and Bauer, R. B. (1960). Archives of Neurology, 2,27 .

Nagashima, C. (1970). Fournal of Neurosurgery, 32, 512.

Prensky, A. L., and Davis, D. O. (1970). Neurology (Minneapolis), $20,945$. Salmon, M. L., Winkelman, J. Z., and Gay, A. J. (1968). Fournal of the American Medical Association, 206, 85.

Schoenberg, B. S., Whisnant, J. P., Taylor, W. F., and Kempers, R. D. (1970). Neurology (Minneapolis), 20, 181 .

Silversides, J. L. (1954). Proceedings of the Royal Society of Medicine, 47, 290. Sprofkin, B. E., and Blakey, H. H. (1956). Archives of Internal Medicine, 98, 617 .

Stewart-Wallace, A. M. (1964). British Medical Yournal, $2,1528$.

(1966). Fournal of Neurology, Neurosurgery and Psychiatry, 29, 241.

Wells, C. E., and Timberger, R. J. (1961). Archives of Neurology, 4, 268.

Williams, D. and Wilson, T. G. (1962). Brain, 85, 741 .

Wood, M. W., and Murphey, F. (1969). Fournal of Neurosurgery, 30, 260.

\section{PRELIMINARY COMMUNICATIONS}

\section{Selective Proximal Vagotomy with and without Pyloroplasty}

\author{
C. WASTELL, J. F. COLIN, \\ J. I. MACNAUGHTON, J. GLEESON
}

British Medical fournal, 1972, 1, 28-30

\section{Summary}

The early results of a prospective randomized clinical trial of selective proximal vagotomy with and without gastric drainage in a total of 36 patients are reported. In spite of adequate average acid reduction and little evidence of gastric retention two definite recurrent ulcers have occurred in the 16 patients who did not have a pyloroplasty. Further trials of the effect of selective proximal vagotomy without gastric drainage are necessary before the procedure is widely adopted.

\section{Introduction}

Truncal vagotomy was introduced on a firm scientific basis by Dragstedt and Owens (1943). Since then it has been constantly criticized because of the severe postoperative symptoms developed by a few patients. This has led to a series of refinements to the original operation, the latest of which is that of selective proximal vagotomy. Before this can be accepted as a procedure suitable for patients with a chronic duodenal ulcer, two questions require an answer: (1) is selective proximal vagotomy effective in curing duodenal ulcer? and (2) is a gastric drainage operation necessary?

\section{Method}

To answer these questions we prepared a consecutive series of 36 males suffering from uncomplicated chronic duodenal ulcer, prospectively randomized into two treatment groups. In

Westminster Medical School, Gordon Hospital, London S.W.1 C. WASTELL, M.S., F.R.C.S., Honorary Consultant and Senior Lecturer in Surgery

. F. COIIIN, F.R.C.S.ED., Surgical Registrar

I. MACNAUGHTON, B.SC., Biochemist

J. GLEESON, M.R.C.P., P.F.R., Consultant Radiologist the first group of 16 patients selective proximal vagotomy alone was performed and in the second group of 20 patients selective proximal vagotomy plus a modified Finney pyloroplasty was the operation. All operations were carried out by the same person. The first patient was accepted into the series in August 1970 and the 36th in April 1971, providing a follow-up of between 3 and 12 months.

Before operation the peak acid output under pentagastrin stimulation was measured, and after operation, on approximately Days 5, 9, and 10, a barium swallow and meal, an insulin response, and a repeat peak acid output were measured. From the gastric function tests for acid secretion, the volume of fasting juice was also obtained. After operation this was taken as the mean of the values obtained when measuring the peak acid output and when measuring insulin response. The insulin responses were analysed by using Hollander's original criteria with the addition of a second hour's collection so that the result was negative, early positive (within 60 minutes after insulin), or late positive (60-120 minutes after insulin).

\section{Operation}

The technique used for selective proximal vagotomy is described briefly. Immediately after the induction of anaesthesia, which was carried out without atropine premedication, the patient was given 0.6 microgramme of pentagastrin per kilogramme body weight, intramuscularly.

After laparotomy the antrum was defined by using a $\mathrm{pH}$ probe passed orally into the stomach, enabling the $\mathrm{pH}$ of the surface of the mucosa to be sampled by manipulation of the probe through the anterior wall of the stomach. This procedure was facilitated by inflating the stomach slightly and so separating the anterior from the posterior wall. Generally, the boundary point between the antrum and the body, which was clearly definable in only half the cases, lay 5 to $7 \mathrm{~cm}$ from the pylorus. If the boundary could not be clearly defined it was taken as the point just proximal to the last clearly seen branch of the anterior nerve of the lesser curve (the nerve of Latarjet).

The vagotomy is performed by dividing the entire neurovascular inflow to the lesser curve from the boundary point, working proximally close to the stomach wall, to a position just short of the oesophagogastric junction. The dissection is then carried across the front of the stomach to its junction with the oesophagus on the left. Finally, the back of the oesophagus and stomach are cleared. The end result of this dissection is to denude the lesser curve of the stomach (see 